\title{
Comprehensive Study on Key Pollen Allergens
}

\author{
Pavan Santhosh Guptha Vusthepalli ${ }^{1}$, Gnana Sri Deepika Vusthepalli ${ }^{1}$, \\ Anupama Ammulu Manne ${ }^{2}$, Sreeja Nannapaneni ${ }^{1}$, Suryanarayana Veeravilli ${ }^{3}$, \\ Rajeswari Setti ${ }^{4}$ and Praveen Kumar Vemuri ${ }^{1 *}$
}

${ }^{1}$ Department of Biotechnology, Koneru Lakshmaiah Education Foundation, Guntur - 522 303, Andhra Pradesh, India.

2Department of Civil Engineering, PVP Siddhartha Institute of Technology, Vijayawada - 520 007, Andhra Pradesh, India.

${ }^{3}$ Department of Humanities and Basic Sciences, Aditya Engineering College, JNTU, Kakinada - 533 002, Andhra Pradesh, India.

${ }^{4}$ Department of Computer Science Engineering, VR Siddhartha Engineering College, Vijayawada - 520 007, Andhra Pradesh, India.

\begin{abstract}
Pollens are typically the primary reason for seasonal hypersensitivity caused in many people that are released by a hundred different species of plants for fertilization. Not all pollens are the same or have the same effect on human beings, there are those worse than others. The human body works out on a defence mechanism by creating certain reactions against those offensive pollens as a response by the immune system. The allergic reactions include sneezing, coughing, wheezing, itching, red-watery swelled eyes, runny nose, inflammation in the nasal passage frequently leading to rhinitis, asthma, skin irritation, and other respiratory disorders. This study is intended to acquire knowledge about a few plants with high allergenic properties along with their major allergens. It is evident that the pollination of the plants varies from season to season as it depends on various factors such as species, weather, and geographical location. Understanding these high allergenic plants with respect to their varying factors and cross-reacting properties is the purpose of this study. It is an effort to obtain deeper insights into these common pollen offenders.
\end{abstract}

Keywords: Pollens, Allergy, Immune system, Hazel, Birch, Ragweed

*Correspondence: vemuripraveen@kluniversity.in

(Received: July 9, 2021; accepted: January 6, 2022)

Citation: Vusthepalli PSG, Vusthepalli GSD, Manne AA, et al. Comprehensive Study on Key Pollen Allergens. J Pure Appl Microbiol. 2022;16(1):110-115. doi: 10.22207/JPAM.16.1.26

C The Author(s) 2022. Open Access. This article is distributed under the terms of the Creative Commons Attribution 4.0 International License which permits unrestricted use, sharing, distribution, and reproduction in any medium, provided you give appropriate credit to the original author(s) and the source, provide a link to the Creative Commons license, and indicate if changes were made. 


\section{INTRODUCTION}

The current review outlines the highly allergenic pollens that generally come from three significant groups of plants namely, trees, weeds, and grass. Various species of all three groups produce millions of pollens per day during flowering season that affect nearly $40 \%$ of sensitized people. ${ }^{1}$ Most people show sensitization towards only one species although it is normal for individuals to react to more than one type of plant pollen as similar protein might be exchanged by some certain pollens. Nearly 60-75 percent of individuals afflicted by allergic rhinitis have indicated a reaction to weed pollens, $40 \%$ of those individuals have been affected by grass pollen and only about $10 \%$ have registered a response to tree pollen. ${ }^{2}$ Allergenic trees which are usually absent in tropical regions ${ }^{3}$ produce dry and weightless pollens that are carried away by the wind to far places. Trees are geographically less concentrated and do not flourish in all environments comparative to grass and weeds. The plants that are categorized as weeds are generally disruptive and unwanted ones that neither fall in the group of trees nor grasses. Weeds have no aesthetic appeal but show immense cross-reaction as they have of calcium-binding proteins. ${ }^{4}$ Grass pollens generally work their way in late spring and summer. Nearly 11 groups of allergens, in the grass pollen, are characterized in more than one species. ${ }^{5}$

Hazel

Hazel is widespread in forests, hedges, and plantations in the northern hemisphere. Also found as mild shrubs or trees, woodlands, grows in plains to highlands, especially along forest boundaries. The blooming period of hazel goes from January and lasts up until April. Contorta (Corylus avellana), Turkish hazel (Corylus colurna), Filbert (Corylus maxima), are some of the most common and widespread species of hazel, primarily present as embellished plants. These are prevalent in more frigid regions of Europe and West Asia. The allergenicity of hazel is mild with moderate potency, toxicity, and presence of the allergen. The allergen generally exhibits crossreactivity among hazelnut and birch or also alder and hornbeam. ${ }^{6}$ Cor a 1 is the major hazel allergen and displays a significant level of homology towards the Bet $v 1$, major birch allergen which highlights the cross-reactivity. ${ }^{7}$ Cor a 1 is a heat- sensitive protein found in both hazel and hazelnut ${ }^{8}$ whose involvement impacts the detection of hazelnut allergy. ${ }^{9}$ The allergenicity towards Cor a 1 labels a pollen-food syndrome that is conflated with oropharyngeal abnormalities. ${ }^{10}$ There are very often local reactions connected with individuals that are solely sensitized to Cor a 1 and are also tolerant of fried hazelnuts. ${ }^{11}$

Birch

Birch which has high allergenicity exhibits regular and conspicuous cross-reactivity with plants of Fagales order, hazel, mugwort, and ragweed (weeds), timothy and rye (grass), ${ }^{12}$ etc. Among foods, apples, kiwi, ${ }^{13}$ stone fruits, carrots, a few nuts, and celery ${ }^{14}$ all seem to be potential factors for food allergies combined with this pollen. During the spring, the most common airborne allergens are produced by birch pollens that are released in millions and spread up to 100 yards by the wind. The flowering period of birch is from April to May that sometimes extends till June. Birch is a taiga plant usually absent in the Mediterranean climate including nearly 50 species, 12 of which are available in North America. The Bet $v 1$ major allergen is named after the natural and widespread Betula verrucosa (common birch) native to Central Europe. Bet v 1 triggers slight effects of oral allergic reactions which are normally activated by apple, plum, cherry, allergens that have structural similarity with it. ${ }^{15}$ The homology of Bet $v 1$ is closely related to that of Cor a 1 (Hazel) and Cas s 1 (European chestnut) ${ }^{16}$ with a substantially identical sequence of amino acids, thereby inducing similar allergenicity. Based on regional proximity to birch pollen, receptor activation to the cross-reactive allergen from birch pollen differs and is mostly found in birch specific areas.

\section{Ragweed}

The ragweed plants, with a flowering season from August to September, are the most effective source of allergies among the weeds that are most active during the late spring and fall months. Common ragweed (Ambrosia artemisiifolia) is the native allergen source and is the major cause of allergic rhinitis in North America ${ }^{17}$ that shows its effect there on almost one in five people. These allergies also were spread through parts of Europe mainly Austria, Italy, and also in Asia. ${ }^{18}$ Roughly a billion pollen 
grains can be unveiled by one individual ragweed plant, ${ }^{19}$ but only a few pollen grains per $\mathrm{m}^{3}$ are necessary to cause inflammation, often contributing to both dermatitis and asthma. ${ }^{20}$ The ragweed pollens that are usually spread by air are also distributed through tainted bird food and ruderal environments. Ragweed pollen has high allergenicity and pays responsibility for the seasonal or fall hay fever. Amb a 1 being the major allergen of the ragweed pollen contributes to $90 \%$ of the allergenic behavior within the plant. ${ }^{21}$ Environmental conditions have a significant effect on the nature of the main allergen, ${ }^{22}$ and Amb a 1 affects more than 90 percent of ragweed-sensitized patients. ${ }^{23}$ Ragweed pollen has shown crossreactivity with Asteraceae sunflower, goldenrod, and other plants in its genus. Cross-reactivity was also identified by comparison of Amb a 1 with a closely related mugwort weed allergen Art $v 6$ as of nearly $65 \%$ sequence similarity. ${ }^{24}$

\section{Mugwort}

Starting from July until September is the blooming period which also varies in a few south European countries from November to April. The mugwort pollens effect is high and widespread through the northern hemisphere as herbaceous plants or shrubs on fertile land spaces. The most common type of mugwort that shows high allergenicity is the Artemisia vulgaris (common wormwood) which are grown all over the northern regions except for the high-temperature dry places. The major pollen of common mugwort Art $v 1$ shows an unexceptional homology with a purified protein of ragweed making the patients allergic to Art v 1 also react to Amb a $4 .{ }^{25}$ In certain countries of Europe and Asia, the main mugwort pollen is accountable for IgE-mediated adverse allergic reactions. ${ }^{26} 87 \%$ of celery allergic people, $52 \%$ of carrot allergic people, and $26 \%$ of caraway seed allergic people also show hypersensitivity towards mugwort leading to the concept of the celery-carrot-mugwort-birch-spice syndrome. ${ }^{27,28}$ Mugwort shares common epitopes with other tree pollens like birch, olive, Italian funeral cypress, and pine. ${ }^{29}$ Cross-reactivity is also observed between the alder tree and mugwort due to the presence of calcium-binding proteins in either.

\section{Rye-grass}

Originating in Europe, though rye-grass is now commonly available, and grown in the temperate regions and islands. The rye-grass is the first meadow cultivated that can be a pasture for grazing. The seasonal blooming of rye-grass starts from May and lasts until July almost the entire summer. The grass that causes the most hypersensitivity among the family of sweet grasses is perennial rye-grass (Lolium perenne) that has Lol p 1 as its main allergen that is responsible for type I allergies. ${ }^{30}$ Immense cross-reactivity is exhibited by this grass with many other species

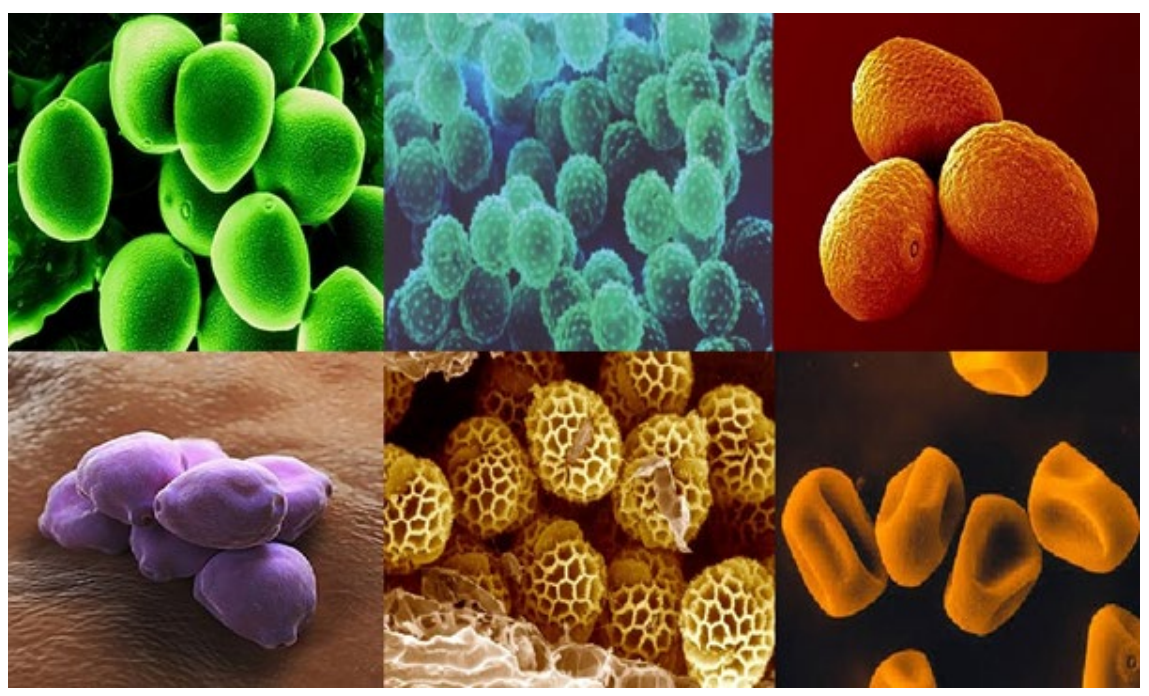

Fig. 1. Top - Birch, Ragweed, Ryegrass. Bottom - Hazel, Mugwort, Timothy grass pollen, adopted from Marcos JV et. al., ${ }^{40}$. 
and also within the family especially with canary grass. ${ }^{31}$ Rye-grass pollens are induced with group 1 allergens that show high homology with Pha a 1 , a major allergen of canary grass including $88.8 \%$ of sequence similarity. Also, with timothy grass major pollen $\mathrm{Phl} p 1$ with a sequence identity of $86.6 \%{ }^{32}$ The allergenicity of rye-grass pollen is almost as similar to that of cocksfoot grass that shows nearly $76 \%$ similarity. ${ }^{33}$ Group 5 allergen that is usually not present in all grasses, acquires epitopes that involve cross-reactivity with group 1 allergen of timothy grass (Phl p 1) and rye-grass (Lol p 1) respectively. ${ }^{34}$ Ryegrass also is induced with group 2, group 4, and group 9 allergens. Rye-grass pollen sensitization is worldwide, patients were affected with various allergic diseases like as allergic rhinitis reported in Switzerland, children in New Zealand affected by asthma ${ }^{35}$ also causing allergic conjunctivitis in many other parts of the world like Netherlands, Germany and South Africa.

\section{Timothy grass}

Timothy grass is one of the common grasses which generally grows on a wide range in meadows or fields that is cultivated as pasture generally for animal grazing. The flowering phase of timothy grass begins in the early summer and ends around midsummer which is usually the period used for hay removal. Timothy grass which can grow well in chilly and muggy climates has an origin in Europe, North Asia, and Africa which spread across America and Australia as well. With differing protein content every season, the impact of allergens in timothy grass will also vary on the affected person. ${ }^{36}$ Timothy grass is by far the only one from which a complete set of allergens are derived amongst the grasses and were cloned. $\mathrm{Phl} \mathrm{p} 1$ is the major group 1 allergen of the Phleum pratense (Timothy grass) that shows cross-reactions mainly between group 1 allergens derived from various grasses, corns, and other monocotyledons. ${ }^{37}$ The group 13 allergen of Timothy grass includes the main allergen in grasses that express IgE cross-reactivity, being similar to the calcium-binding protein of timothy grass. ${ }^{38}$ Timothy grass shows cross-reactivity with bahiagrass pollen ${ }^{39}$ and also share lgE epitopes with weed plants like mugwort and ragweed. Timothy grass pollens have resulted in hypersensitivity to various places like Sweden, Norway, and other European regions with nasal symptoms like asthma and rhinitis in cold weather.

\section{CONCLUSION}

The current studies offer a glimpse into some of the intensely reactive pollens that are responsible for hypersensitivity within individuals. Recent investigations also provide information about the major allergens of the respective plant play their part in various allergies. The evidence suggests that the major allergens of different plants involve cross-reactivity or co-sensitization due to homology in their amino acid sequences. The main allergens of these hyper-allergic plants and their distribution across many parts of the world and sign that the extent of pollination changes along with the seasons, weather, and geography of that particular plant are assessed. Advancement in analyzing the pollen sensitization, interpretation, and characterization has enhanced our insights into the plant pollen or allergen sensitization mechanism in susceptible individuals.

\section{ACKNOWLEDGMENTS}

The authors thank the management of KLEF, PVPSIT, AEC and VRSEC for continuous support during the work.

\section{CONFLICTS OF INTEREST}

The authors declare that there is no conflict of interest.

\section{AUTHORS' CONTRIBUTION}

PSGV and GSDV conceptualized and designed the study. AAM did the literature review and drafted the manuscript. SN and SV critically revised the article. RS checked the references. PKV edited and approved the final manuscript for publication.

\section{FUNDING} None.

\section{DATA AVAILABILITY}

All datasets generated or analyzed during this study are included in the manuscript. 


\section{ETHICS STATEMENT}

Not applicable.

\section{REFERENCES}

1. Singh JS. The biodiversity crisis: a multifaceted review. Current Science. 2002:638-647.

2. Skoner DP. Allergic rhinitis: definition, epidemiology, pathophysiology, detection, and diagnosis. J Allergy Clin Immunol Pract. 2001;108(1):S2-S8. doi: 10.1067/ mai.2001.115569

3. Asam C, Hofer H, Wolf M, Aglas L, Wallner M. Tree pollen allergens-an update from a molecular perspective. Allergy. 2015;70(10):1201-1211. doi: 10.1111/all.12696

4. Bertin C, Senesac AF, Rossi FS, DiTommaso A, Weston LA. Evaluation of selected fine-leaf fescue cultivars for their turfgrass quality and weed suppressive ability in field settings. Hort Technology. 2009;19(3):660-668. doi: 10.21273/HORTSCI.19.3.660

5. Vemuri PK, Yarlagadda DSV, Tatineni J. Characterization of Sesamum indicum proteins and its immunogenic activity. Drug Invention Today. 2019;11(7): 1740-1744.

6. Boddakayala N, Bodiga S, Bodiga VL, et al. Conformational Epitope Prediction of Birch Betv 1 and Hazel Cor A1 Towards B-Cells. J Pharm Res Int. 2021:146-159. doi: 10.9734/jpri/2021/v33i28A31519

7. Smeekens JM, Bagley K, Kulis M. Tree nut allergies: Allergen homology, cross-reactivity, and implications for therapy. Clin Exp Allergy. 2018;48(7):762-772. doi: 10.1111/cea.13163

8. Akkerdaas JH, Schocker F, Vieths $\mathrm{S}$, et al. Cloning of oleosin, a putative new hazelnut allergen, using a hazelnut cDNA library. Mol Nut Food Res. 2006;50(1):18-23. doi: 10.1002/mnfr.200500147

9. Croote D, Quake SR. Food allergen detection by mass spectrometry: the role of systems biology. NPJ Syst Biol Appl. 2016;2(1):1-10. doi: 10.1038/npjsba.2016.22

10. Ludman S, Jafari-Mamaghani M, Ebling R, Fox AT, Lack $\mathrm{G}$, Toit GD. Pollen food syndrome amongst children with seasonal allergic rhinitis attending allergy clinic. Pediatr Allergy Immunol. 2016;27(2):134-140. doi: 10.1111/pai.12504

11. Worm M, Hompes S, Fiedler EM, Illner AK, Zuberbier T, Vieths S. Impact of native, heat-processed and encapsulated hazelnuts on the allergic response in hazelnut-allergic patients. Clin Exp Allergy. 2009;39(1):159-166. doi: 10.1111/j.13652222.2008.03143.x

12. Vemuri PK, Talluri B, Panangapalli G, Veeravalli $S$, Bodiga VL. Purification and characterization of Parthenium hysterophorus flower proteins that exhibit inherent immunological responses. Int I Green Phar. 2016;10(4):S1-S4.

13. Daniel EM, Krupnick AS, Heur YH, Blinzler JA, Nims RW, Stoner GD. Extraction, stability, and quantitation of ellagic acid in various fruits and nuts. $J$ Food Compost Anal. 1989;2(4):338-349. doi: 10.1016/08891575(89)90005-7

14. Katz $Y$, Gutierrez-Castrellon P, Gonzalez MG, Rivas R, Lee BW, Alarcon P. A comprehensive review of sensitization and allergy to soy-based products.
Clin Rev Allergy Immunol. 2014;46(3):272-281. doi: 10.1007/s12016-013-8404-9

15. Turner PJ, Baumert JL, Beyer K, et al. Can we identify patients at risk of life-threatening allergic reactions to food? Allergy. 2016;71(9):1241-1255. doi: 10.1111/ all.12924

16. Mills EC, Sancho Al, Rigby NM, Jenkins JA, Mackie AR. Impact of food processing on the structural and allergenic properties of food allergens. $\mathrm{Mol}$ Nut Food Res. 2009;53(8):963-969. doi: 10.1002/ mnfr.200800236

17. Wolters LJ, Heijstek MW, Holm PW, Elberink HNGO. Bariatric surgery: relevant cofactor for systemic foodborne allergic reactions. J Allergy Clin Immunol Pract. 2019;7(2):704-707. doi: 10.1016/j.jaip.2018.10.028

18. Vemuri PK, Veeramachaneni RC, Nukarapu M, Sardarji DK. Immunological characterization of immunoglobulin $\mathrm{G}$ towards house dust allergens. Int J Biot Biochem. 2009;5(3):189-196. doi: 10.37622/ IJBB/5.3.2009.189-196

19. Mobs C, Slotosch C, Loffler H, Jakob T, Hertl M, Pfutzner W. Birch pollen immunotherapy leads to differential induction of regulatory $T$ cells and delayed helper $T$ cell immune deviation. J Immunol. 2010;184(4):21942203. doi: $10.4049 /$ jimmunol.0901379

20. Sicherer SH, Sampson HA. Food allergy: epidemiology, pathogenesis, diagnosis, and treatment. J Allergy Clin Immunol. 2014;133(2):291-307. doi: 10.1016/j. jaci.2013.11.020

21. Carlson G, Coop C. Pollen food allergy syndrome (PFAS): a review of current available literature. Ann Allergy Asthma Immunol. 2019;123(4):359-365. doi: 10.1016/j.anai.2019.07.022

22. Prescott SL. Early-life environmental determinants of allergic diseases and the wider pandemic of inflammatory noncommunicable diseases. J Allergy Clin Immunol. 2013 Jan 1;131(1):23-30. doi: 10.1016/j. jaci.2012.11.019

23. Asero R, Wopfner N, Gruber P, Gadermaier G, Ferreira F. Artemisia and Ambrosia hypersensitivity: co-sensitization or co-recognition? Clin Exp Allergy. 2006;36(5):658-665. doi: 10.1111/j.13652222.2006.02477.x

24. Jahn-Schmid B, Hauser M, Wopfner N, et al. Humoral and cellular cross-reactivity between Amb a 1 , the major ragweed pollen allergen, and its mugwort homolog Art v 6. J Immunol. 2012;188(3):1559-1567. doi: 10.4049/jimmunol.1102445

25. Oberhuber $\mathrm{C}, \mathrm{Ma} \mathrm{Y}, \mathrm{W}$ Wopfner $\mathrm{N}$, et al. Prevalence of IgE-binding to Art $v 1$, Art $\vee 4$ and Amb a 1 in mugwort-allergic patients. Int Arch Allergy Immunol. 2008;145(2):94-101. doi: 10.1159/000108134

26. Mansueto P, Montalto G, Pacor ML, et al. Food allergy in gastroenterologic diseases: Review of literature. World J Gastroenterol. 2006;12(48):7744-7752. doi: 10.3748/wjg.v12.i48.7744

27. Ballmer-Weber BK, Vieths $S$, Lüttkopf $D$, Heuschmann $P$, Wüthrich B. Celery allergy confirmed by double-blind, placebo-controlled food challenge: a clinical study in 32 subjects with a history of adverse reactions to celery root. J Allergy Clin Immunol. 2000;106(2):373-378. doi: 10.1067/mai.2000.107196 
28. Sybert VP, McCauley E. Turner's syndrome. $N$ Engl J Med. 2004;351(12):1227-1238. doi: 10.1056/ NEJMra030360

29. Baldrick P, Richardson D, Woroniecki SR, Lees B. Pollinex ${ }^{\circledR}$ Quattro Ragweed: safety evaluation of a new allergy vaccine adjuvanted with monophosphoryl lipid A (MPL $\left.{ }^{\circledR}\right)$ for the treatment of ragweed pollen allergy. J Appl Toxicol. 2007;27(4):399-409. doi: 10.1002/ jat.1223

30. White JF, Bernstein DI. Key pollen allergens in North America. Ann Allergy Asthma Immunol. 2003;91(5):425435. doi: 10.1016/S1081-1206(10)61509-8

31. Vemuri PK, Talluri B, Dedaniya A, et al. Innate immunological activity of immunoglobulin $Y$ towards Parthenium hysterophorus leaf proteins. I Chem Pharm Res. 2016;8(3):459-464.

32. Knox B, Suphioglu C. Environmental and molecular biology of pollen allergens. Trends Plant Sci. 1996;1(5):156-164. doi: 10.1016/S13601385(96)80051-3

33. Mastrorilli C, Cardinale F, Giannetti A, Caffarelli C. Pollen-food allergy syndrome: a not so rare disease in childhood. Medicina. 2019;55(10):641. doi: 10.3390/ medicina55100641

34. Ong EK, Singh MB, Knox RB. Aeroallergens of plant origin: molecular basis and aerobiological significance. Aerobiologia. 1995;11(4):219-229. doi: 10.1007/

\section{BF02447202}

35. Dapul-Hidalgo G, Bielory L. Climate change and allergic diseases. Ann Allergy Asthma Immunol. 2012;109(3):166-172. doi: 10.1016/j.anai.2012.02.008

36. Blando J, Bielory L, Nguyen V, Diaz R, Jeng HA. Anthropogenic climate change and allergic diseases. Atmosphere. 2012;3(1):200-212. doi: 10.3390/ atmos 3010200

37. Sozener ZC, Cevhertas L, Nadeau K, Akdis M, Akdis CA. Environmental factors in epithelial barrier dysfunction. J Allergy Clin Immunol. 2020;145(6):1517-1528. doi: 10.1016/j.jaci.2020.04.024

38. Zhang R, Duhl T, Salam MT, et al. Development of a regional-scale pollen emission and transport modeling framework for investigating the impact of climate change on allergic airway disease. Biogeosciences. 2014;11(6):1461-1478. doi: 10.5194/bg-11-1461-2014

39. Davies JM, Bright ML, Rolland JM, O'Hehir RE. Bahia grass pollen specific IgE is common in seasonal rhinitis patients but has limited cross-reactivity with Ryegrass. Allergy. 2005;60(2):251-255. doi: 10.1111/j.13989995.2005.00663.x

40. Marcos JV, Nava R, Cristobal G, et al. Automated pollen identification using microscopic imaging and texture analysis. Micron. 2015;68:36-46. doi: 10.1016/j. micron.2014.09.002 